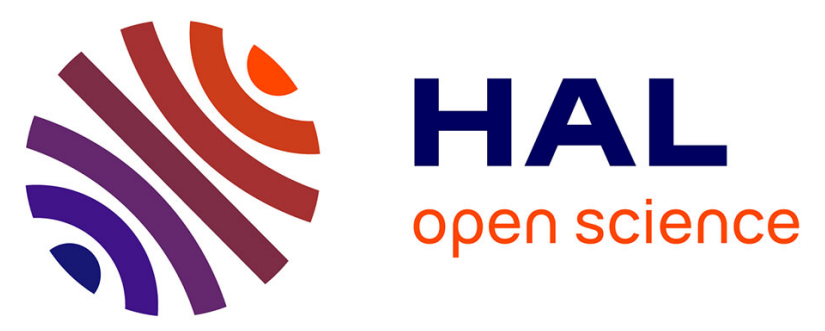

\title{
Pathogenicity study of Mycoplasma hyorhinis and M. flocculare in specific-pathogen-free pigs pre-infected with M. hyopneumoniae
}

Sarah Fourour, Véronique Tocqueville, Frédéric Paboeuf, Gérald Lediguerher, Nadège Morin, Isabelle Kempf, Corinne Marois-Créhan

\section{- To cite this version:}

Sarah Fourour, Véronique Tocqueville, Frédéric Paboeuf, Gérald Lediguerher, Nadège Morin, et al.. Pathogenicity study of Mycoplasma hyorhinis and M. flocculare in specific-pathogen-free pigs pre-infected with M. hyopneumoniae. Veterinary Microbiology, 2019, 232, pp.50 - 57. 10.1016/j.vetmic.2019.04.010 . hal-03485001

\section{HAL Id: hal-03485001 https://hal.science/hal-03485001}

Submitted on 21 Dec 2021

HAL is a multi-disciplinary open access archive for the deposit and dissemination of scientific research documents, whether they are published or not. The documents may come from teaching and research institutions in France or abroad, or from public or private research centers.
L'archive ouverte pluridisciplinaire HAL, est destinée au dépôt et à la diffusion de documents scientifiques de niveau recherche, publiés ou non, émanant des établissements d'enseignement et de recherche français ou étrangers, des laboratoires publics ou privés.

\section{(ㄷ)(1) $\$$}

Distributed under a Creative Commons Attribution - NonCommerciall 4.0 International 


\section{Highlights}

- Experimental study of pesticides heterogeneous degradation by ozone

- The increase of the surface coating slows the degradation kinetics down

- The surface coating is influenced by the nature of particles

\section{Graphical abstract}

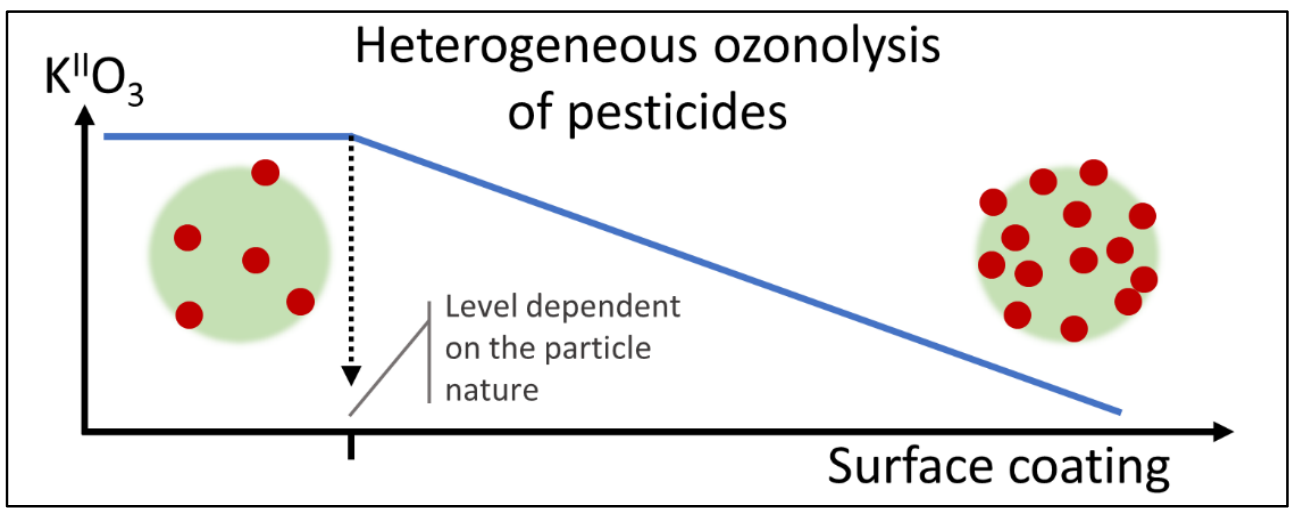

29 Keywords

30 Atmosphere, Surface coating, Degradation, Heterogeneous, Ozone, Pesticides 
32 A fraction of the atmospheric pesticides can be adsorbed on particles surface according to their physicochemical properties. After adsorption, pesticides can undergo heterogeneous reactivity with atmospheric oxidants such as ozone, but the influence of the pesticide surface coating (i.e., the percentage of the particle surface covered by pesticide molecules) on the degradation kinetics is not well-understood. To estimate the importance of this phenomenon, the influence of the surface coating level in pesticides on the heterogeneous ozonolysis of cyprodinil, deltamethrin, permethrin, and pendimethalin adsorbed on hydrophobic and hydrophilic silicas was investigated. Surface coating level varied from $0.3 \%$ to $15 \%$ of a monolayer. Generally, the increase of the surface coating level induced a slower degradation of the pesticides above $1 \%$ to $3 \%$ of a monolayer. This decrease was attributed to a shielding effect. More aggregates of pesticides form with increasing surface coating leading to lower accessibility for ozone to the adsorbed pesticide molecules. Moreover, it was observed that the particle type could play a role in the influence of the surface coating level on the degradation rates. Results obtained will contribute to a better understanding of the atmospheric fate of pesticides and semi-volatile organic compounds in the particulate phase and show the importance of working with consistent surface coating level in order to compare the obtained degradation constants. 


\section{Introduction}

51 Numerous studies have reported the presence of pesticides in the atmosphere in concentrations ranging from a few picograms per cubic meter to hundreds of nanograms per cubic meter (Coscollà et al. 2010; Estellano et al. 2015; Lopez et al. 2017; Désert et al. 2018; Villiot et al. 2018). At the same time, many adverse effects of pesticides on human health (Clementi et al. 2008; Hatcher et al. 2008; Marks et al. 2010; Inserm 2013; Parrón et al. 2014; Kim et al. 2017) and on the environment (Santadino et al. 2014; Carvalho 2017) have been evidenced. In particular, harmful health effects associated with pesticide exposure by inhalation of ambient air have been highlighted (Lee et al. 2002; Li et al. 2014; Lopez et al. 2017). Therefore, it is important to improve our understanding of the atmospheric fate of 60 pesticide.

In the atmosphere, pesticides are distributed between aqueous, gaseous, and particulate phases according to their physicochemical properties. Nevertheless, they are generally poorly present in the aqueous phase due to the low water solubility of most of them. Numerous pesticides are semi-volatile compounds, and a fraction of them is adsorbed on the atmospheric particles surface (Sauret et al., 2008). Pesticides can react with atmospheric oxidants such as ozone, hydroxyl $(\mathrm{OH})$ and nitrate $\left(\mathrm{NO}_{3}\right)$ radicals. Their atmospheric reactivity in the gas phase has been widely studied and the modeling software AOPWIN ${ }^{\mathrm{TM}}$ (Atmospheric Oxidation Program for Microsoft Windows, Software, Meylan and Howard 1993) allows to estimate their rate constants with $\mathrm{OH}$ radicals and, to a lesser extent with ozone. For the particle phase, a few studies have investigated the heterogeneous degradation of pesticides with ozone

71 (Mattei et al, 2018 and references therein), OH radicals (Socorro et al. 2016 and references therein), and $\mathrm{NO}_{3}$ radicals (Mattei 2019b, submitted). The influences of relative humidity and particle type on the pesticide reactivity have already been demonstrated (Mattei et al. 2018, 
2019a). However, the influence of the amount of pesticide on the surface on the degradation kinetics was poorly investigated.

Before studying heterogeneous reactivity, authors calculate or estimate the particle surface coating level in the organic compounds under study. Assuming the formation of a uniform monolayer on the particle surface, these calculations are usually expressed in percentage of a monolayer. For pesticides, the total surface coating (i.e., the percentage of the particle surface covered by pesticide molecules, considering all the compounds adsorbed on the surface) varies greatly from a study to another, from $0.04 \%$ (Pflieger et al. 2009) to 69\% (Al Rashidi et al. 2013).

To the best of our knowledge, only one study focusing on the heterogeneous ozonolysis of chlorpyrifos (insecticide) adsorbed on sand particles investigated and demonstrated the influence of the particle coating level on pesticide degradation (El Masri et al., 2016). The cited work shows that the increase of surface coating level from $6 \%$ to $60 \%$ of a monolayer slows the heterogeneous degradation kinetics down. If very few data are available for pesticides, further information on the influence of the surface coating level was published on other semi-volatile organic compounds such as Polycyclic Aromatic Hydrocarbons (PAH) adsorbed on fused silica plates (Wu et al. 1984), on nonactivated silica gel (Alebic-Juretic et al. 1990), on soot particles (Pöschl et al. 2001), and on graphite and silica particles (Perraudin et al. 2007; Miet et al. 2009). For PAH, the reaction rates seem to be also influenced by the surface coating level.

The aim of this study is to investigate the influence of the surface coating level $(0.3$ to $15 \%$ of a monolayer) on the heterogeneous ozonolysis of four pesticides (cyprodinil, deltamethrin, permethrin, and pendimethalin) adsorbed on two types of model mineral particles (hydrophobic and hydrophilic silicas). These four pesticides were selected based on their presence in the atmosphere up to a dozen of $n g \mathrm{~m}^{-3}$ (Désert et al., 2018), on their toxicity 
(APVMA, 2017), and on their distribution between the gas and particle phases (AOPWIN ${ }^{\mathrm{TM}}$, Meylan and Howard 1993). Moreover, they have been the subject of numerous studies of reactivity towards ozone (Socorro et al. 2015; Mattei et al. 2018) and OH radicals (Socorro et al. 2016; Mattei et al. 2019). The two particle types were chosen as models for mineral atmospheric particles. They have different surface properties but a very close composition and morphology. For this work, particles coated with a various amount of pesticides were exposed in realistic conditions of temperature, relative humidity, and gaseous ozone concentration.

\section{Materials and methods}

\subsection{Chemicals}

Cyprodinil (purity 99.8\%), deltamethrin (99.7\%), pendimethalin (98.8\%), and permethrin (98.3\%) were purchased from Sigma-Aldrich (PESTANAL®, analytical standard) and were used as received. The chemical structures of the pesticides under study are depicted in Supplementary Information (SI) Fig. SI1 and their physicochemical properties are given in SI Table SI1.

\subsection{Particles}

Atmospheric mineral aerosols were mimicked using two commercial silica particles: AEROSIL R812 (Degussa) hereafter referred to as "hydrophobic silica", and AEROSIL 255 (Evonik Industries) referred to as "hydrophilic silica". Composition: hydrophobic and hydrophilic silicas $\left(>99.8 \mathrm{wt} \%\right.$ ) contain primarily $\mathrm{SiO}_{2}$. Particle size: the average primary particle size of hydrophobic and hydrophilic silica particles ranges from $5 \mathrm{~nm}$ to $50 \mathrm{~nm}$ (Evonik, 2015). However, most of them can be arranged as agglomerates with an aggregate size coarsely measured mainly around $5 \mu \mathrm{m}$, sometimes up to $25 \mu \mathrm{m}$. Field observations show that pesticides are distributed in the fine $(0.1-1 \mu \mathrm{m})$, ultrafine $(0.03-0.1 \mu \mathrm{m})$, and coarse $(1-$ $10 \mu \mathrm{m})$ particle size fraction, and no pesticides were detected in the size fraction $>10 \mu \mathrm{m}$ 
123 (Coscollà et al., 2014, 2013; Xu et al., 2011). Specific surface area (SSA; BET method):

124 hydrophobic and hydrophilic silica particles have a specific surface area of $(260 \pm 30) \mathrm{m}^{2} \mathrm{~g}^{-1}$ 125 and $(255 \pm 25) \mathrm{m}^{2} \mathrm{~g}^{-1}$, respectively (Evonik, 2015). Surface chemistry and hygroscopicity:

126 surfaces of hydrophobic particles are mainly covered by siloxanes whereas hydrophilic silica

127 particles are mainly covered by silanols groups. Silanol groups have a hydrophilic nature but

128 the siloxane groups are chemically inert and hydrophobic.

\subsection{Particles coating}

130 Hydrophobic and hydrophilic silica particles were independently coated with pesticides

131 according to a liquid/solid adsorption. In an amber Pyrex bulb of $500 \mathrm{~cm}^{3}, 600 \mathrm{mg}$ of particles

132 were mixed with a pesticide solution in dichloromethane (each of the 4 pesticides at a

133 concentration of $20 \mathrm{mg} \mathrm{L}^{-1}$ in dichloromethane for HPLC, $\geq 99.8 \%$, Sigma-Aldrich) of a

134 variable volume according to the coating level required and $40 \mathrm{~mL}$ of dichloromethane. After

135 a 5-min ultrasound treatment, dichloromethane was evaporated by a rotary evaporator

136 (Rotavapor R-114, Büchi) at $40^{\circ} \mathrm{C}$ and 850 mbar. For a given volume of solution, this process

137 allows a reproducible coating of the pesticides on the particle's surface (Socorro et al. 2015).

138 The percentage of particle surface coated with pesticides was calculated considering the

139 following assumptions: the particles surface coating is uniform and below a monolayer. The

140 pesticide molecule is considered as a sphere and its radius $\left(r_{i}, \mathrm{~cm}\right)$ is calculated by Equation

141 (1):

$142 \quad r_{i}=\sqrt[3]{\frac{3 \times V_{m}}{4 \times \pi \times N_{A}}}$

143 where $V_{m}$ is the molar volume $\left(\mathrm{cm}^{3} \mathrm{~mol}^{-1}\right)$ of pesticide and $N_{A}$ is the Avogadro number. The

144 molar volume is calculated using Advanced Chemistry Development (ACD/Labs) Software 145 V11.02 (@ 1994-2014 ACD/Labs). 
$146 S_{i}$ is the surface $\left(\mathrm{cm}^{2}\right)$ covered by the pesticide under study. It is defined by Equation (2)

147 where $n$ is the amount of adsorbed pesticide (mole):

$148 S_{i}=4 \times \pi \times r_{i}^{2} \times N_{A} \times n$

149 The percentage of the coated aerosol surface $T_{i}(\%)$ by the adsorbed pesticide $i$ is calculated as

150 follow:

$151 \quad T_{i}=\frac{S_{i}}{S_{1}} \times 100$

152 where $S_{1}$ is the silica particle surface $\left(\mathrm{m}^{2} \mathrm{~g}^{-1}\right)$.

153 The total surface coated (including all compounds under study) was calculated by adding

154 individual percentages of the aerosol coated surface:

$155 T=\Sigma T_{i}$

156 As a result, the percentage of the particle surface coated with total pesticide was between

$157 \quad 0.3 \%$ and $15 \%$ of the monolayer according to the different experiments for hydrophobic and

158 hydrophilic silicas, which correspond to pesticide loadings between $0.166 \mathrm{mg} \mathrm{g}^{-1}$ and $8.45 \mathrm{mg}$ $159 \mathrm{~g}^{-1}$.

$160 \quad$ 2.4. Ozonolysis experiments

161 The experimental setup was previously detailed in Socorro et al. (2015) (Fig. 1). 


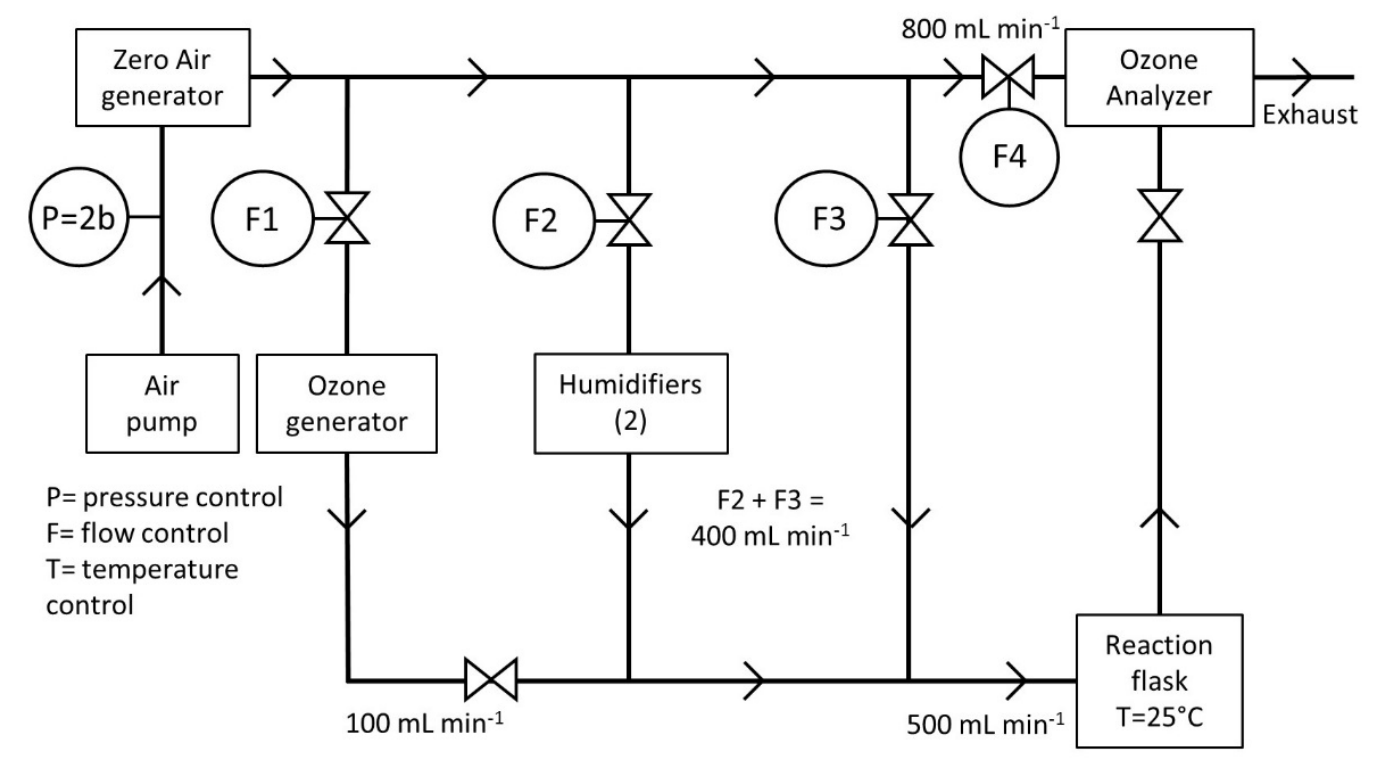

162

Fig. 1: Experimental setup to study the heterogeneous ozonolysis of pesticides

164 Briefly, a $500 \mathrm{~cm}^{3}$ amber Pyrex bulb containing about $500 \mathrm{mg}$ of dried particles coated with

165 the mixture of pesticides was fixed to a modified rotary evaporator and placed in a

166 thermostated water bath $\left(25 \pm 1{ }^{\circ} \mathrm{C}\right)$. Ozone was generated by flowing purified air through an

167 ozone generator (UVP, LLC Upland, UK). Particles coated with pesticides were exposed to

168 an air flux containing an ozone mixing ratio of $410 \mathrm{ppb}$ (i.e., $1.03 \cdot 10^{13}$ molecules $\mathrm{cm}^{-3}$ )

169 constantly measured with a photometric ozone analyzer $\left(\mathrm{O}_{3} 41 \mathrm{M}\right.$, Environnement S.A). The

170 relative humidity $(\mathrm{RH})$ was set at $55 \% \pm 2 \%$. The humidity level was reached by mixing dry

171 and wet gaseous fluxes of purified air. Relative humidity was measured with a humidity probe

172 (Hydrolog NT, Rotronic, USA, uncertainty 2\% RH) and the total of all air fluxes in the

173 reaction flask was $500 \mathrm{~mL} \mathrm{~min}{ }^{-1}$. Experiments lasted for $26 \mathrm{~h}$.

\section{$174 \quad$ 2.5. Extraction and pesticides quantification}

175 During ozone exposure, $30 \mathrm{mg}$ aliquots of particles were regularly sampled in order to 176 quantify the remaining adsorbed pesticides on their surface. Each $30 \mathrm{mg}$ aliquot of particles

177 was individually introduced in a $33 \mathrm{~mL}$ stainless steel cell with an internal standard solution 
178 (Triphenyl phosphate, 99.9\%, Sigma-Aldrich) and pesticides were extracted by accelerated

179 solvent extraction (ASE 350, Dionex) with dichloromethane. Then, the extracts were

180 concentrated under a nitrogen flow with a concentration workstation (TurboVap II, Biotage).

181 The obtained solutions were analyzed with gas chromatography coupled to tandem mass

182 spectrometry (GC/MS-MS), with a Trace GC Ultra (Thermo Scientific) coupled to a TSQ

183 Quantum ${ }^{\mathrm{TM}}$ Triple Quadrupole (Thermo Scientific) using electron impact ionization (70 eV).

184 More details about ASE extraction, concentration, and GC/MS-MS analysis are available in

185 Socorro et al. (2015).

\section{2.6. Determination of second-order rate constants and half-lives toward ozone}

187 Considering that ozone was continuously drifting in the reactor and that it was, therefore, 188 present in excess, a pseudo-first-order kinetic constant was assumed:

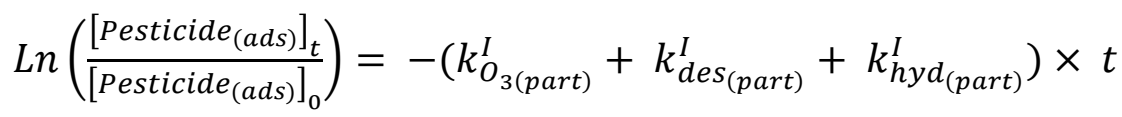

190 where $k_{O_{3(\text { part }}}^{I}\left(\mathrm{~s}^{-1}\right)$ is the pseudo-first-order rate constant of the reaction between ozone and

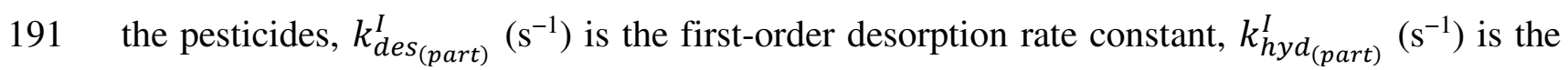

192 pseudo-first-order hydrolysis rate constant, $t(\mathrm{~s})$ is the time of ozone exposure, and

$193 \frac{\left[\text { Pesticide }_{(\text {ads })}\right]_{t}}{\left[\text { Pesticide }_{(\text {ads })}\right]_{0}}$ is the pesticide concentration normalized to the initial pesticide concentration.

194 The pseudo-first-order reaction rate constants for the heterogeneous ozonolysis of the particle-

195 phase pesticides were determined by analyzing their corresponding temporal profiles in a time

196 frame from 0 to $26 \mathrm{~h}$, for $410 \mathrm{ppb}$ ozone mixing ratio (i.e., $1.03 \cdot 10^{13}$ molecules $\mathrm{cm}^{-3}$ ).

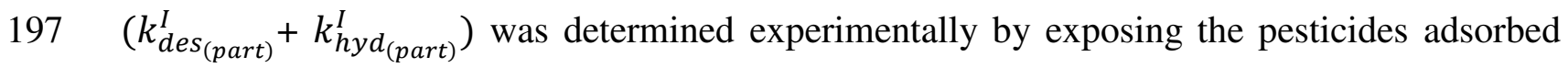

198 on the surface of particles to a flow of humidified air, using the same experimental conditions

199 as for the ozonolysis experiments but in absence of ozone. In order to determine the second- 
200 order rate constants $k_{O_{3(\text { part })}}^{I I}\left(\mathrm{~cm}^{3}\right.$ molecule $\left.\mathrm{s}^{-1}\right)$, the experimental pseudo-first-order 201 reaction rate constants $k_{O_{3(p a r t)}}^{I}$ were plotted as a function of the ozone concentrations. To 202 simulate the kinetic mechanisms of the heterogeneous reactivity, the second-order rate 203 constants $k_{O_{3(p a r t)}}^{I I}$ were calculated assuming only one ozone mixing ratio, i.e., $410 \mathrm{ppb}$, using 204 a Langmuir-Rideal model, as done in previous studies concerning pesticide degradation by 205 ozone and hydroxyl radicals (Mattei et al., 2018, 2019a). Indeed, the linearity of the first order 206 kinetic constants versus the ozone concentration (with ozone mixing ratios ranging from 215 207 ppb to $917 \mathrm{ppb}$ ) was already demonstrated in Socorro et al. (2015). The second-order rate 208 constant was calculated as follows:

$k_{O_{3(\text { part })}}^{I I}=k_{O_{3(\text { part })}}^{I} /\left[O_{3(\text { gas })}\right]$

210 where $\left[O_{3 \text { (gas) }}\right]$ is the constant ozone mixing ratio of $410 \mathrm{ppb}$ used in the experiments, which 211 is representative of a highly polluted atmosphere (Finlayson-Pitts and Pitts 2009).

\section{3. Results and discussion}

\subsection{Degradation kinetics}

214 In order to study the influence of pesticide surface coating level on the heterogeneous 215 ozonolysis kinetics, four pesticides (cyprodinil, deltamethrin, permethrin, and pendimethalin) were adsorbed together on mineral model particles (hydrophobic and hydrophilic silicas) at

217 five levels of surface coating ( $T=0.3 \%, 1 \%, 1.5 \%$ (only hydrophilic silica), $2.8 \%$ (only 218 hydrophobic silica), $10 \%$, and $15 \%$ of a monolayer) and exposed to $410 \mathrm{ppb}$ of ozone. As an 219 example, Fig. 2 represents the degradation kinetics for permethrin adsorbed on hydrophilic 220 silica at different surface coating levels. Those data are not corrected by the loss of permethrin 221 induced by hydrolysis and desorption. After correcting the raw data, pseudo-first-order and 222 then second-order degradation rate constants were calculated according to section 2.6 
223 (Determination of second-order rate constants and half-lives toward ozone). Pesticides were 224 exposed together to ozone and the corrections with the hydrolysis and desorption kinetic rate 225 constants were applied for all of them. The results show that the four pesticides were 226 degraded by ozone and their second-order kinetic rate constants ranged from $(1.1 \pm 0.9) \cdot 10^{-19}$ $227 \mathrm{~cm}^{3}$ molecules ${ }^{-1} \mathrm{~s}^{-1}$ (permethrin, $T=15 \%$, hydrophilic silica) to $(1.2 \pm 0.1) \cdot 10^{-18} \mathrm{~cm}^{3}$ 228 molecules $^{-1} \mathrm{~s}^{-1}$ (deltamethrin, $T=1 \%$, hydrophilic silica).

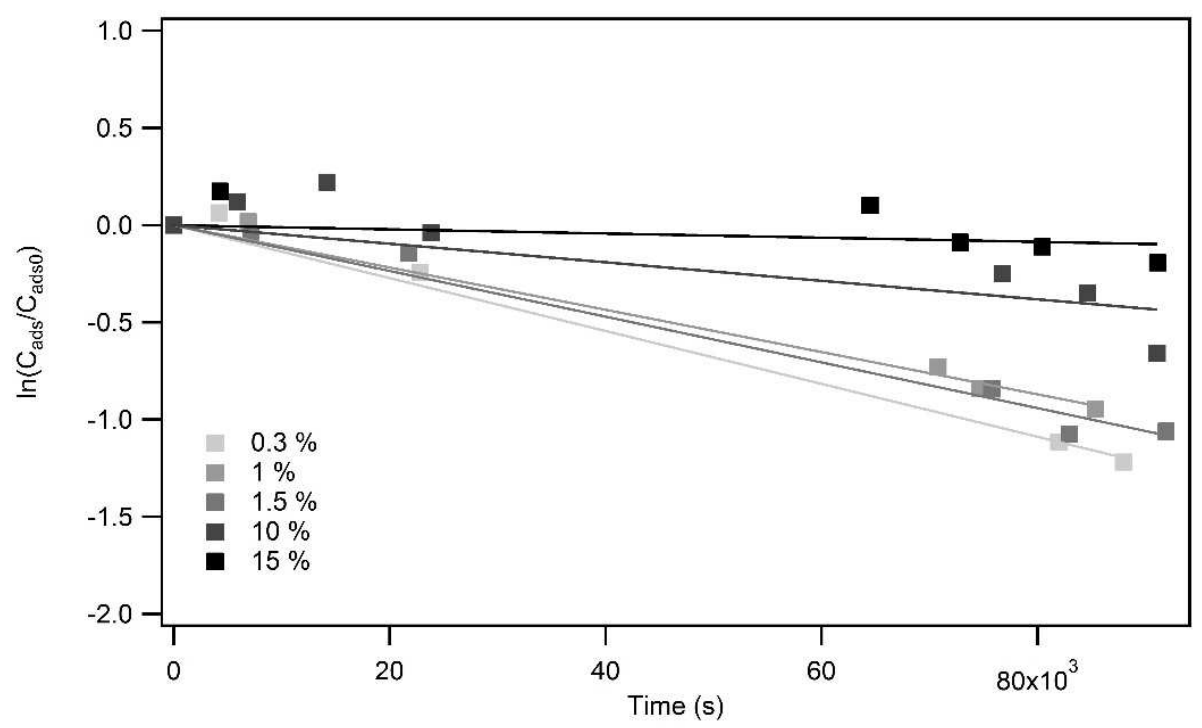

230 Fig. 2: Raw data of the degradation kinetics for permethrin on hydrophilic silica exposed to $410 \mathrm{ppb}$ of ozone adsorbed at five surface coating levels

\subsection{Influence of the surface coating for pesticides adsorbed on hydrophobic silica}

233 Fig. 3 presents the second-order kinetic rate constants for the ozonolysis of the four pesticides 234 under study adsorbed on hydrophobic silica as a function of the surface coating level that 235 ranged from $0.3 \%$ to $15 \%$ of a monolayer. 


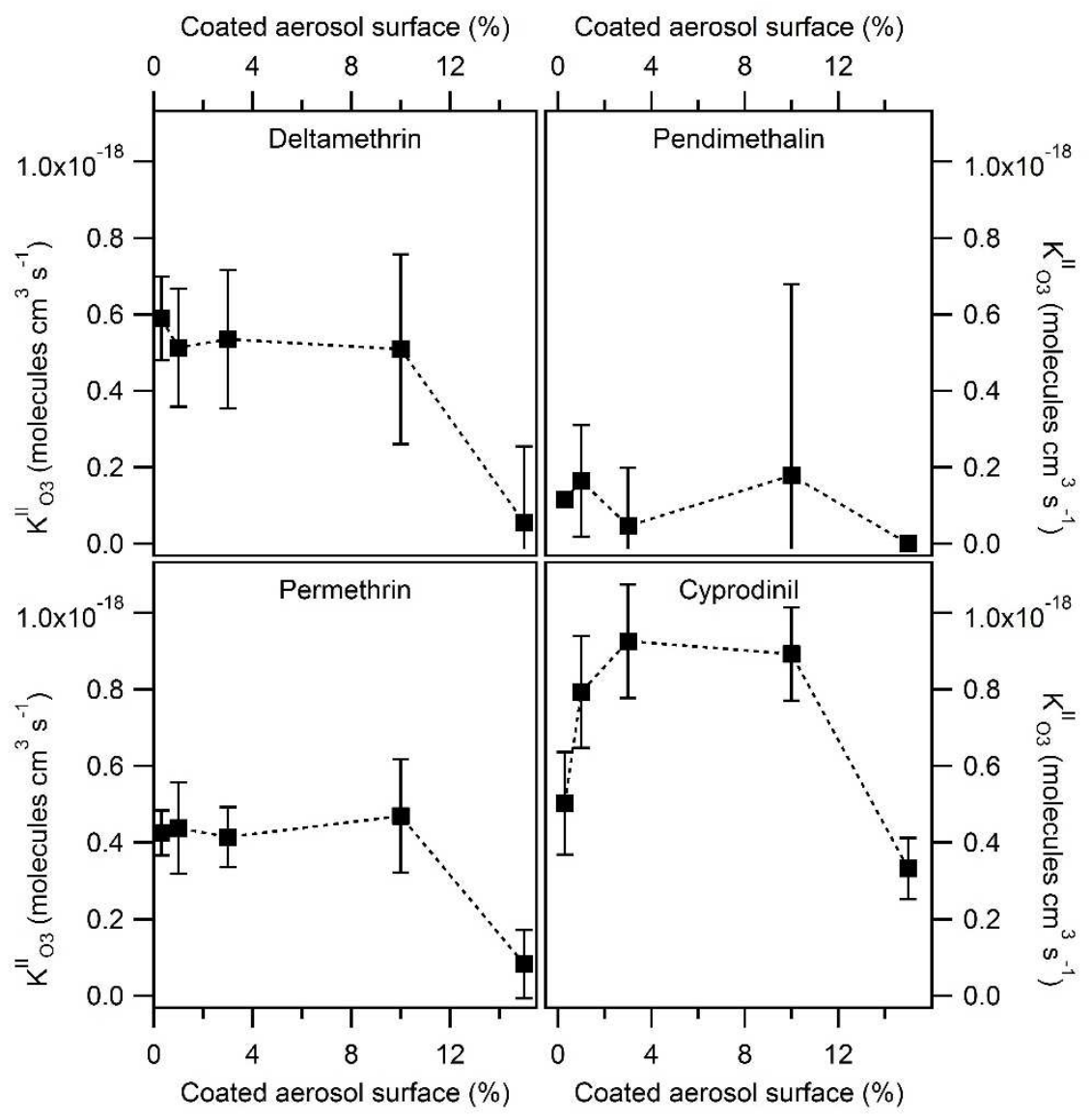

Fig. 3: Second-order kinetic rate constants for the ozonolysis of four pesticides adsorbed on hydrophobic silica at 5 surface coating levels from $0.3 \%$ to $15 \%$ of a monolayer.

239 When they were adsorbed on hydrophobic silica, all four pesticides were degraded by ozone.

240 However, two different types of behavior toward the surface coating level were observed 241 according to the pesticide nature.

242 Firstly, deltamethrin, permethrin, and pendimethalin had a parallel behavior; second-order 243 kinetic rate constants were approximatly stable given the uncertainties until a given surface 244 coating level, and above this level, their degradation kinetics decreased with increasing 245 surface coating level. Second-order kinetic rate constants obtained for deltamethrin and 246 permethrin, two pyrethroid insecticides, adsorbed on hydrophobic silica were similar, i.e., (5.4 $247 \pm 1.8) \cdot 10^{-19} \mathrm{~cm}^{3}$ molecules ${ }^{-1} \mathrm{~s}^{-1}$ and $(4.7 \pm 1.2) \cdot 10^{-19} \mathrm{~cm}^{3}$ molecules ${ }^{-1} \mathrm{~s}^{-1}$ from $0.3 \%$ to $10 \%$ 248 of surface coating, respectively. No statistically significant degradation was observed at $15 \%$ 
surface coating. The kinetic behavior of pendimethalin was close to those of permethrin and 250 deltamethrin with constant kinetic rates from $0.3 \%$ to $1 \%$ of surface coating (about $(1.4 \pm 0.8)$ $\cdot 10^{-19} \mathrm{~cm}^{3}$ molecules $^{-1} \mathrm{~s}^{-1}$ ) and not statistically significant (i.e., negligible degradation rate constants) from $2.8 \%$ to $15 \%$ surface coating.

253 Secondly, the behavior of cyprodinil was different from those of deltamethrin, permethrin, 254 and pendimethalin. With increasing coating level, second-order kinetic rate constants 255 increased and then decreased. The second-order kinetic rate constant for cyprodinil at $0.3 \%$ of 256 surface coating $\left((5.0 \pm 1.3) \cdot 10^{-19} \mathrm{~cm}^{3}\right.$ molecules $\left.{ }^{-1} \mathrm{~s}^{-1}\right)$ was slower than those obtained from $2571 \%$ to $10 \%$ (about $(8.7 \pm 1.4) \cdot 10^{-19} \mathrm{~cm}^{3}$ molecules $\left.{ }^{-1} \mathrm{~s}^{-1}\right)$. Cyprodinil degradation rate was 258 then the slowest at $15 \%$ of surface coating $\left((3.2 \pm 0.8) \cdot 10^{-19} \mathrm{~cm}^{3}\right.$ molecules $\left.{ }^{-1} \mathrm{~s}^{-1}\right)$.

\subsection{Influence of the surface coating for pesticides adsorbed on hydrophilic silica}

When they were adsorbed on hydrophilic silica, all four pesticides were degraded by ozone. However, results concerning cyprodinil were associated with high uncertainties (about 10

262 times higher than for the other pesticides). Therefore, results for cyprodinil are not included in 263 the discussion.

264 Fig. 4 presents the second-order kinetic rate constants for the ozonolysis of deltamethrin, 265 pendimethalin, and permethrin adsorbed on hydrophilic silica as a function of the surface 266 coating level from $0.3 \%$ to $15 \%$ of a monolayer. 


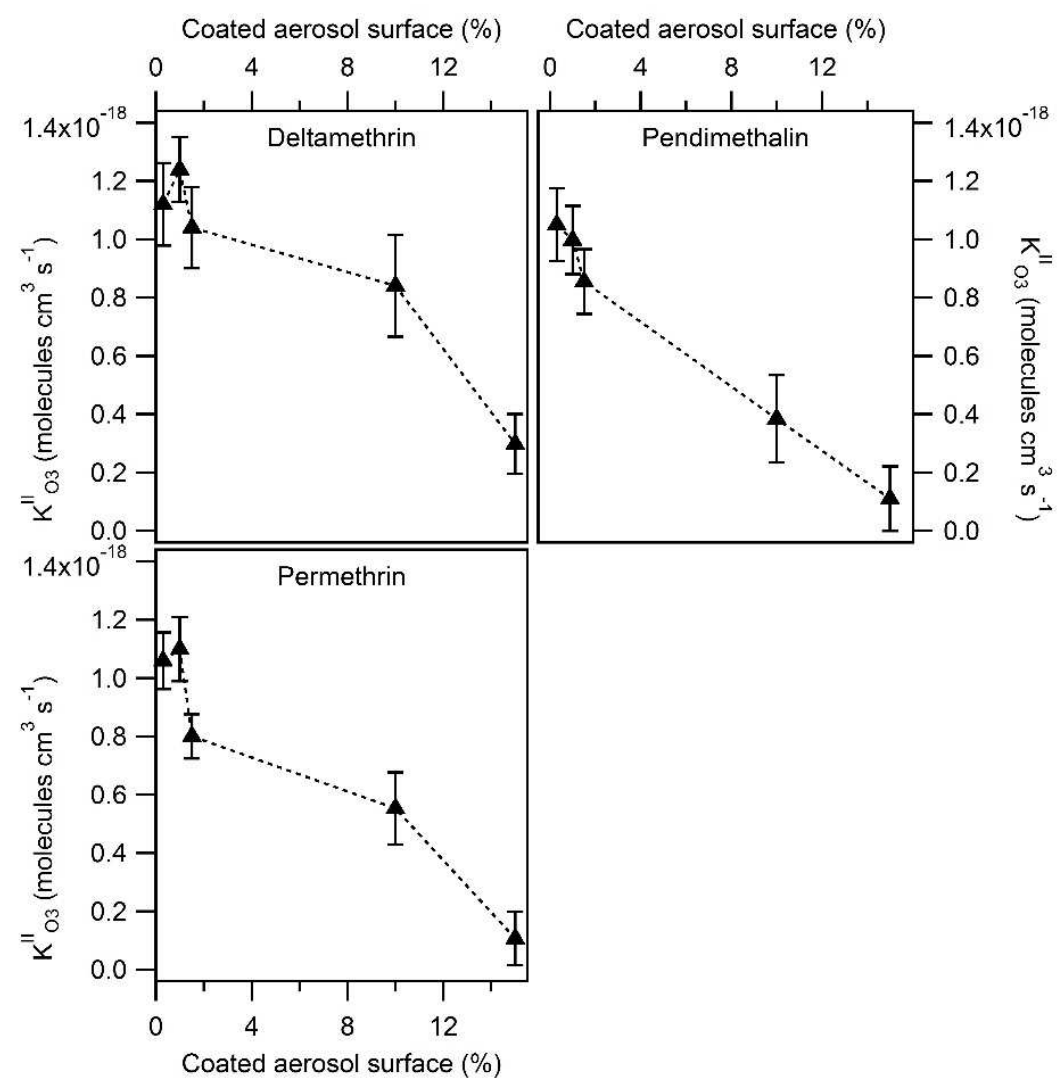

268 Fig. 4: Second-order kinetic rate constants for the ozonolysis of deltamethrin, pendimethalin, 269 and permethrin adsorbed on hydrophilic silica at 5 surface coating levels from $0.3 \%$ to $15 \%$ of 270 a monolayer.

271 The three pesticides (deltamethrin, permethrin, and pendimethalin) followed the same trend 272 given the uncertainties, i.e., steady degradation rates at low surface coating level (from $0.3 \%$ 273 to $1.5 \%)$ and a gradual decrease of the degradation at higher surface coating level $(\geq 1.5 \%)$.

274 The second-order degradation rate constant of pendimethalin was stable at $0.3 \%$, $1 \%$, and $2751.5 \%$ of surface coating (about $(9.7 \pm 1.2) \cdot 10^{-18} \mathrm{~cm}^{3}$ molecules $^{-1} \mathrm{~s}^{-1}$ ), 2 times slower at $10 \%$ 276 of surface coating $\left((3.8 \pm 1.5) \cdot 10^{-19} \mathrm{~cm}^{3}\right.$ molecules $\left.{ }^{-1} \mathrm{~s}^{-1}\right)$, and 9 times slower at $15 \%$ of 277 surface coating $\left((1.1 \pm 1.1) \cdot 10^{-19} \mathrm{~cm}^{3}\right.$ molecules $\left.{ }^{-1} \mathrm{~s}^{-1}\right)$. The same trend was observed for 278 permethrin and deltamethrin. The second-order degradation rate constants for permethrin and 279 deltamethrin were about $(1.0 \pm 0.1) \cdot 10^{-18} \mathrm{~cm}^{3}$ molecules $\mathrm{s}^{-1}$ and about $(1.1 \pm 0.1) \cdot 10^{-18} \mathrm{~cm}^{3}$ 280 molecules ${ }^{-1} \mathrm{~s}^{-1}$ from $0.3 \%$ to $1.5 \%$ of surface coating, $(5.5 \pm 1.2) \cdot 10^{-19} \mathrm{~cm}^{3}$ molecules $\mathrm{s}^{-1}$ 
and $(8.4 \pm 1.8) \cdot 10^{-19} \mathrm{~cm}^{3}$ molecules ${ }^{-1} \mathrm{~s}^{-1}$ at $10 \%$ of surface coating, and $(1.1 \pm 0.9) \cdot 10^{-19} \mathrm{~cm}^{3}$ molecules ${ }^{-1} \mathrm{~s}^{-1}$ and $(3.0 \pm 1.0) \cdot 10^{-19} \mathrm{~cm}^{3}$ molecules $\left.^{-1} \mathrm{~s}^{-1}\right)$ at $15 \%$ of surface coating, respectively, which represent a degradation 9 and 3 times slower between the highest and lowest rate constant values.

\subsection{Discussion on the influence of the surface coating on the degradation kinetics}

Aggregate shielding effect

On both hydrophilic and hydrophobic silicas, the degradation kinetics were generally slowed down by an increase of the surface coating level (El Masri et al., 2016). Indeed, when the surface coating increases, the probability of pesticides forming aggregates also increases. This can induce an 'aggregate shielding' effect, making a fraction of the pesticide molecules less accessible to oxidation by ozone. The shielding effect was observed in this study as a decrease of the kinetic constants with increasing surface coating level, and even with the total inhibition of the reactivity of some of the pesticides at the highest surface coating level tested.

To our knowledge, only a few studies investigated the influence of the surface coating level of organic compounds on their heterogeneous degradation by ozone. One study only focused on the degradation of a pesticide (chlorpyrifos) (El Masri et al., 2016). Other studies took an interest on the heterogeneous degradation of PAH and especially of benzo[a]pyrene (BaP) by ozone ( Wu et al. 1984; Alebic-Juretic et al. 1990; Pöschl et al. 2001; Perraudin et al. 2007; Miet et al. 2009).

The heterogeneous ozonolysis of chlorpyrifos adsorbed on sand particles has been shown to be strongly influenced by the surface coating level of the pesticide (El Masri et al., 2016). This was possibly due to the use of high pesticide concentrations adsorbed on particles ranging from $10 \mu \mathrm{g} \mathrm{g}^{-1}$ to $100 \mu \mathrm{g} \mathrm{g}^{-1}$ which correspond to a surface coating level of $6 \%$ to $60 \%$ of a monolayer. Degradation rate constants were found to be 70 times slower at $60 \%$ of 
surface coating level than at $6 \%$. This decrease in kinetic constants followed an exponential trend, explained by the authors as a shielding effect induced by the increasing coating level.

307 Our results also show a decrease of the kinetic constants, however, coating levels employed in our study were lower (from $0.3 \%$ to $15 \%$ ) than theirs (from $6 \%$ to $60 \%$ ). In the present work 309 the decrease in kinetic constants was observed only above a given surface coating level (1\% 310 to 3\%) whereas El Masri et al. (2016) observed the decrease of the kinetic constants over the 311 entire surface coating level range from $6 \%$ to $60 \%$. This allows us to show that, with 312 increasing surface coating level, degradation rates are at first constant, as observed in our 313 study, and then, they start to decrease, as observed in our study and by El Masri et al. (2016).

314 It could be expected that the 'aggregate shielding' effect would decrease as the compound is 315 degraded. However, this would only be the case if the degradation products would desorb to 316 the gas phase. Yet, it was previously shown that the heterogeneous ozonolysis of deltamethrin 317 and permethrin leads to degradation products including some that remain in the particle phase 318 (Socorro et al. 2016). Also, the study of the degradation of chlorpyrifos (El Masri et al., 2016) 319 also focuses on one of its degradation products: chlorpyrifos oxon. This degradation product 320 is not reacting with ozone, and it remains in the particle phase, acting as a barrier to ozone 321 diffusion. In this way, even as pesticides are degraded by ozone, the 'aggregate shielding' 322 effect can remain.

323 The heterogeneous ozonolysis of PAH on diverse surfaces (silica gel, silica particles, fused 324 silica plates, graphite, and soot particles) was also shown to be influenced by the surface 325 coating level, with kinetic constants slowed down by the increase of the surface coating ( $\mathrm{Wu}$ 326 et al. 1984; Alebic-Juretic et al. 1990; Pöschl et al. 2001; Perraudin et al. 2007; Miet et al. 327 2009). Unfortunately, most of those studies only considered the variation in the degradation 328 on the degradation kinetics between the sub-monolayer and super-monolayer coating and 329 therefore underline the difference in reactivity for PAH in the bulk phase and the dispersed 
phase due to shielding effect. Nevertheless, Wu et al. (1984) pointed out that the kinetic constants for the ozonolysis of PAH adsorbed on fused silica plates is proportional to the ozone concentration for low surface coating level (one-third of a monolayer) but that this cannot be extended for higher surface coatings (aggregates or bulk phase). Again, this indicates that under a given surface coating level, no aggregates are formed, and so kinetic constants are independent of the surface coating level and that above this surface coating level, the formation of aggregates induces a shielding effect affecting the degradation kinetics.

\section{Influence of particle nature}

338 Generally, literature is consistent with the fact that the increase of the surface coating level

339 induces a decrease in the degradation kinetics constants, as observed in this study. However, 340 some studies mentioned a shielding effect appearing above the level of the monolayer coating 341 ( Wu et al. 1984; Alebic-Juretic et al. 1990; Pöschl et al. 2001; Perraudin et al. 2007; Miet et 342 al. 2009). In this study, as well as in the study by Wu et al. (1984), the shielding effect was

343 observed far below a monolayer. Aggregate formation is therefore possible for a low 344 concentration of adsorbed compounds (i.e., 1-1.5\% of a monolayer). Figures 3 and 4 show 345 that the surface coating level for which second-order kinetic rate constants start to decrease 346 seems to be dependent on the particle type (it is lower on hydrophilic silica than on 347 hydrophobic silica). This probably shows that the nature of the interaction between organic 348 compound and particle is crucial in the formation of aggregates. Indeed, if there is a good 349 affinity, the organic compound is likely to adsorb homogeneously on the surface, but in case 350 of poor affinity, organic compounds are likely to adsorb on a few sites and then to form 351 aggregates around the prior-adsorbed compounds. Therefore, the nature of the particle and of 352 the adsorbed compound also plays a role in the effect of the surface coating level.

353 In the present work, carried out with silica particles, the kinetic profiles do not show any 354 plateau, thereby suggesting that the shielding effect is only partial (it only significantly slows 
down the degradation kinetics but does not entirely hinder degradation). But some studies

356 concerning the heterogeneous degradation of $\mathrm{PAH}$ by oxidants such as ozone, $\mathrm{NO}_{2}$ and 357 hydroxyl radicals reported the presence of a plateau in the degradation time trends (Esteve et al. 2004, 2006; Perraudin et al. 2007; Miet et al. 2009). This means that, some molecules are not accessible to the oxidant, because they are hidden by other PAH or by particle phase degradation products. In those studies, this plateau phenomenon was observed on the surface of organic particles (soot, diesel particles) but not on the surface of silica particles, possibly because of a different disposition of PAH molecules according to the nature of the surface. Thus, because of different surface repartition of molecules, the particle type can influence the degradation kinetics.

Lastly, our previous study (Mattei et al. 2018) showed a faster ozonolysis of deltamethrin, permethrin, and pendimethalin when adsorbed on hydrophilic silica than hydrophobic silica at a surface coating of about $3 \%$ of a monolayer in the same experimental conditions as in this study, explained by a greater affinity of ozone for hydrophilic silica than hydrophobic silica. This observation is also valid for low surface coating $(\leq 10 \%)$, as can be seen in Figure 3 and 4. However, at $15 \%$ surface coating, kinetic constants were comparable whatever the particle surface was. This shows that for a high surface coating level, the particle nature does not have an influence on the degradation kinetics because the 'aggregate shielding' effect dominates over the particle nature effect.

\section{Atmospheric implications and conclusion}

375 The influence of surface coating between $0.3 \%$ and $15 \%$ of a monolayer on the heterogeneous ozonolysis kinetics of four commonly used pesticides (cyprodinil, deltamethrin, permethrin, 377 and pendimethalin) was investigated. Degradation rate constants were slowed down when the 378 surface coating level increased above $1 \%$ to $3 \%$ of a monolayer, by a factor of maximum 10 , due to shielding effect. This effect is due to the formation of aggregates of the organic 
compound on the particle surface, which makes the reaction between the oxidant and the

381 molecules included in the aggregates more difficult or impossible. The surface coating level 382 for which this shielding effect appears depends on the surface type, probably because of the 383 variability of affinity between the organic compound and the surface.

384 As already mentioned for relative humidity and particle type (Mattei et al. 2018), these results 385 highlight the need to be consistent in surface coating when doing experimental determination 386 of kinetic rate constants in order to be able to compare results from different laboratories and 387 different studies.

388 Moreover, this work was conducted regarding the degradation of pesticides by ozone, but it 389 could be likely that the shielding effect observed could also affect the degradation kinetic 390 rates of pesticides with other atmospheric oxidants such as hydroxyl and nitrate radicals.

391 This study shows that pesticide degradation was slowed down for weak surface coating level 392 (i.e., weak pesticide loading) without taking into account the presence of other SVOC. 393 However, they can also participate to the shielding effect as mentioned for PAH (Wu et al. 394 1984; Alebic-Juretic et al. 1990; Pöschl et al. 2001; Perraudin et al. 2007; Miet et al. 2009). In 395 fact, the highest the surface coating in SVOC is, the slowest their degradation will be, 396 influencing, as a result, the ability of those compounds to spread in the environment and 397 impact air quality.

398 Finally, few field studies measured atmospheric concentrations with respect to particle surface 399 sizes, making it impossible to calculate the real surface coating in SVOC. This shows the need 400 for more field measurements to better describe the real surface coating of pesticides on 401 atmospheric particles.

\section{Acknowledgments}


403 This work has been carried out thanks to the support of the COPP'R project "Modelling of 404 atmospheric contamination by plant protection products at the regional scale" funded by the 405 PRIMEQUAL - AGRIQA « Agriculture et qualité de l'air » program. C. Mattei received a 406 doctoral grant from the French Environment and Energy Management Agency (ADEME) and 407 the Region Provence-Alpes-Côte d'Azur. 
Al Rashidi, M.J., Chakir, A., Roth, E., 2013. Heterogeneous Ozonolysis of Folpet and

Alebic-Juretic, A., Cvitas, T., Klasinc, L., 1990. Heterogeneous Polycyclic Aromatic Hydrocarbon Degradation with Ozone on Silica Gel Carrier. Environ. Sci. Technol. 24:1. https://doi.org/10.1021/es00071a005

APVMA [Australian Pesticide and Veterinary Medicines Authority], 2017. Acceptable Daily Intakes for Agricultural and Veterinary Chemicals. Office of Chemical Safety, Office of Health Protection, Department of Health and Ageing. Australian Government 113p. https://apvma.gov.au/sites/default/files/publication/26796-adi.pdf.

Carvalho, F.P., 2017. Pesticides, environment, and food safety. Food Energy Secur. 6, 48-60. https://doi.org/10.1002/fes3.108

Clementi, M., Tiboni, G.M., Causin, R., La Rocca, C., Maranghi, F., Raffagnato, F., Tenconi, R., 2008. Pesticides and fertility: An epidemiological study in Northeast Italy and review of the literature. Reprod. Toxicol., 36th Annual Conference of the European Teratology Society 26, 13-18. https://doi.org/10.1016/j.reprotox.2008.05.062

Coscollà, C., Colin, P., Yahyaoui, A., Petrique, O., Yusà, V., Mellouki, A., Pastor, A., 2010. Occurrence of currently used pesticides in ambient air of Centre Region (France). Atmos. Environ. 44, 3915-3925. https://doi.org/10.1016/j.atmosenv.2010.07.014

Coscollà, C., Muñoz, A., Borrás, E., Vera, T., Ródenas, M., Yusà, V., 2014. Particle size distributions of currently used pesticides in ambient air of an agricultural Mediterranean area. Atmos. Environ. 95, 29-35. https://doi.org/10.1016/j.atmosenv.2014.06.022

Coscollà, C., Yahyaoui, A., Colin, P., Robin, C., Martinon, L., Val, S., Baeza-Squiban, A., Mellouki, A., Yusà, V., 2013. Particle size distributions of currently used pesticides in a rural atmosphere of France. Atmos. Environ. 81, 32-38. https://doi.org/10.1016/j.atmosenv.2013.08.057

Désert, M., Ravier, S., Gille, G., Quinapallo, A., Armengaud, A., Pochet, G., Savelli, J.-L., Wortham, H., Quivet, E., 2018. Spatial and temporal distribution of current-use pesticides in ambient air of Provence-Alpes-Côte-d'Azur Region and Corsica, France. Atmos. Environ. 192, 241-256. https://doi.org/10.1016/j.atmosenv.2018.08.054

El Masri, A., Laversin, H., Chakir, A., Roth, E., 2016. Influence of the coating level on the heterogeneous ozonolysis kinetics and product yields of chlorpyrifos ethyl adsorbed on sand particles. Chemosphere 165, 304-310. https://doi.org/10.1016/j.chemosphere.2016.09.036

Estellano, V., Pozo, K., Efstathiou, C., Pozo, K., Corsolini, S., Focardi, S., 2015. Assessing levels and seasonal variations of current-use pesticides (CUPs) in the Tuscan atmosphere, Italy, using polyurethane foam disks (PUF) passive air samplers. Environ. Pollut. 205, 52-59. https://doi.org/10.1016/j.envpol.2015.05.002

Finlayson-Pitts, B.J., Pitts, J.N., 2009. Chemistry of the upper and lower atmosphere: theory, experiments, and applications, Nachdr. ed. Academic Press, San Diego, Calif.

Hatcher, J.M., Pennell, K.D., Miller, G.W., 2008. Parkinson's disease and pesticides: a toxicological perspective. Trends Pharmacol. Sci. 29, 322-329. https://doi.org/10.1016/j.tips.2008.03.007

Inserm, 2013. Pesticides : Effets sur la santé - Une expertise collective de l'Inserm.

Kim, K.-H., Kabir, E., Jahan, S.A., 2017. Exposure to pesticides and the associated human health effects. Sci. Total Environ. 575, 525-535. https://doi.org/10.1016/j.scitotenv.2016.09.009 
Lee, S., McLaughlin, R., Harnly, M., Gunier, R., Kreutzer, R., 2002. Community exposures to airborne agricultural pesticides in California: ranking of inhalation risks. Environ. Health Perspect. 110, 1175-1184.

Li, H., Ma, H., Lydy, M.J., You, J., 2014. Occurrence, seasonal variation and inhalation exposure of atmospheric organophosphate and pyrethroid pesticides in an urban community in South China. Chemosphere 95, 363-369. https://doi.org/10.1016/j.chemosphere.2013.09.046

Lopez, A., Yusà, V., Muñoz, A., Vera, T., Borràs, E., Ródenas, M., Coscollà, C., 2017. Risk assessment of airborne pesticides in a Mediterranean region of Spain. Sci. Total Environ. 574, 724-734. https://doi.org/10.1016/j.scitotenv.2016.08.149

Marks Amy R., Harley Kim, Bradman Asa, Kogut Katherine, Barr Dana Boyd, Johnson Caroline, Calderon Norma, Eskenazi Brenda, 2010. Organophosphate Pesticide Exposure and Attention in Young Mexican-American Children: The CHAMACOS Study. Environ. Health Perspect. 118, 1768-1774. https://doi.org/10.1289/ehp.1002056

Mattei, C., Wortham, H., Quivet, E., 2019. Heterogeneous degradation of pesticides by $\mathrm{OH}$ radicals in the atmosphere: Influence of humidity and particle type on the kinetics. Sci. Total Environ. 664, 1084-1094. https://doi.org/10.1016/j.scitotenv.2019.02.038

Mattei, C., Wortham, H., Quivet, E., 2018. Heterogeneous atmospheric degradation of pesticides by ozone: Influence of relative humidity and particle type. Sci. Total Environ. 625, 1544-1553. https://doi.org/10.1016/j.scitotenv.2018.01.049

Meylan, W.M., Howard, P.H., 1993. Computer estimation of the Atmospheric gas-phase reaction rate of organic compounds with hydroxyl radicals and ozone. Chemosphere 26, 2293-2299. https://doi.org/10.1016/0045-6535(93)90355-9

Miet, K., Le Menach, K., Flaud, P.M., Budzinski, H., Villenave, E., 2009. Heterogeneous reactions of ozone with pyrene, 1-hydroxypyrene and 1-nitropyrene adsorbed on particles. Atmos. Environ. 43, 3699-3707. https://doi.org/10.1016/j.atmosenv.2009.04.032

Parrón, T., Requena, M., Hernández, A.F., Alarcón, R., 2014. Environmental exposure to pesticides and cancer risk in multiple human organ systems. Toxicol. Lett., Environmental contaminants and target organ toxicities 230, 157-165. https://doi.org/10.1016/j.toxlet.2013.11.009

Perraudin, E., Budzinski, H., Villenave, E., 2007. Kinetic Study of the Reactions of Ozone with Polycyclic Aromatic Hydrocarbons Adsorbed on Atmospheric Model Particles. J. Atmospheric Chem. 56, 57-82. https://doi.org/10.1007/s10874-006-9042-x

Pflieger, M., Grgić, I., Kitanovski, Z., Nieto, L., Wortham, H., 2011. The heterogeneous ozonation of pesticides adsorbed on mineral particles: Validation of the experimental setup with trifluralin. Atmos. Environ. 45, 7127-7134. https://doi.org/10.1016/j.atmosenv.2011.09.031

Pöschl, U., Letzel, T., Schauer, C., Niessner, R., 2001. Interaction of Ozone and Water Vapor with Spark Discharge Soot Aerosol Particles Coated with Benzo[a]pyrene: O3 and H2O Adsorption, Benzo[a]pyrene Degradation, and Atmospheric Implications. J. Phys. Chem. A 105, 4029-4041. https://doi.org/10.1021/jp004137n

Santadino, M., Coviella, C., Momo, F., 2014. Glyphosate Sublethal Effects on the Population Dynamics of the Earthworm Eisenia fetida (Savigny, 1826). Water. Air. Soil Pollut. 225, 2207. https://doi.org/10.1007/s11270-014-2207-3

Sauret, N., Wortham, H., Putaud, J.-P., Mirabel, P., 2008. Study of the effects of environmental parameters on the gas/particle partitioning of current-use pesticides in urban air. Atmos. Environ. 42, 544-553. https://doi.org/10.1016/j.atmosenv.2007.09.012 
Socorro, J., Gligorovski, S., Wortham, H., Quivet, E., 2015. Heterogeneous reactions of ozone with commonly used pesticides adsorbed on silica particles. Atmos. Environ. 100, 6673. https://doi.org/10.1016/j.atmosenv.2014.10.044

Socorro, J., Durand, A., Temime-Roussel, B., Gligorovski, S., Wortham, H., Quivet, E., 2016. The persistence of pesticides in atmospheric particulate phase: An emerging air quality issue. Sci. Rep. 6. https://doi.org/10.1038/srep33456

Villiot, A., Chrétien, E., Drab-Sommesous, E., Rivière, E., Chakir, A., Roth, E., 2018. Temporal and seasonal variation of atmospheric concentrations of currently used pesticides in Champagne in the centre of Reims from 2012 to 2015. Atmos. Environ. 174, 82-91. https://doi.org/10.1016/j.atmosenv.2017.11.046

Wu, C.H., Salmeen, I., Niki, H., 1984. Fluorescence spectroscopic study of reactions between gaseous ozone and surface-adsorbed polycyclic aromatic hydrocarbons. Environ. Sci. Technol. 18, 603-607. https://doi.org/10.1021/es00126a007

Xu, H., Du, S., Cui, Z., Zhang, H., Fan, G., Yin, Y., 2011. Size distribution and seasonal variations of particle-associated organochlorine pesticides in Jinan, China. J. Environ. Monit. 13, 2605. https://doi.org/10.1039/c1em10394f 